\title{
Effects of on-line hemodiafiltration regimens and dialysate composition on serum concentrations of magnesium and calcium ions
}

\author{
Yusaku Tanaka ${ }^{1 *}$, Hisato Shima ${ }^{2}$, Ryosuke Hatonari ${ }^{1}$, Daisuke Okada ${ }^{1}$, Hiroyuki Michiwaki ${ }^{1}$, Seiichiro Wariishi ${ }^{3}$, \\ Tomohiro Tao ${ }^{1}$ and Jun Minakuchi ${ }^{2}$
}

\begin{abstract}
Background: Low-ionized magnesium and high-ionized calcium levels are associated with increased cardiovascular mortality in patients undergoing dialysis. We examined the effects of the dilution method, substitution volume, and dialysate of on-line hemodiafiltration on the total and ionized magnesium and calcium levels.

Methods: Eighteen patients were randomly assigned to three dialysate groups: two acetic acid dialysate groups and one citrate dialysate group. Five treatment conditions were applied: pre-diluted on-line hemodiafiltration, postdiluted on-line hemodiafiltration, and hemodialysis.

Results: The total and ionized serum levels of magnesium and calcium were evaluated and found to be unaffected by the dilution methods and substitution volumes. The albumin leakage was approximately $3 \mathrm{~g} / \mathrm{session}$ under the pre-dilution and hemodiafiltration conditions, and approximately $4-5 \mathrm{~g} / \mathrm{session}$ under the post-dilution condition. The ionized magnesium concentration decreased in the citrate dialysate group.
\end{abstract}

Conclusion: The on-line hemodiafiltration parameters had a negligible effect on ionized magnesium and calcium; however, the use of citrate dialysate decreased the ionized magnesium levels, probably because of chelation.

Trial registration: 000028172. The study was registered on July 112017.

Keywords: Citrate dialysate, Ionized calcium, lonized magnesium, On-line hemodiafiltration, Standard dialysate

\section{Background}

Excretion of magnesium tends to decline when renal function deteriorates, resulting in an elevated risk of hypermagnesemia [1]. Hemodialysis (HD) treatment typically results in reduced post-dialysis serum magnesium concentration because of the low magnesium concentration in the dialysate $(0.5 \mathrm{mmol} / \mathrm{L})$ [2]. Recent reports have suggested that magnesium in serum prevents

\footnotetext{
* Correspondence: yu-tanaka0724@khg.or.jp

${ }^{1}$ Clinical Engineering Department of Kawashima Hospital, 1-39

Kitasakoichiban-cho, Tokushima, Tokushima 770-0011, Japan

Full list of author information is available at the end of the article
}

vascular calcification, thus reducing the risk of death from cardiovascular diseases $[3,4]$. These findings indicate that it may be important to maintain pre-dialysis serum magnesium concentrations at $2.7-3.0 \mathrm{mg} / \mathrm{dL}$ in patients undergoing HD [3, 4]. These studies have led researchers to reconsider the magnesium concentration during dialysis.

Other research studies have suggested that elevated serum calcium levels are correlated with increased risk of cardiovascular mortality $[5,6]$. Therefore, calcium and magnesium may be important factors affecting prognosis. In Japan, the following four dialysate calcium

(c) The Author(s). 2021 Open Access This article is licensed under a Creative Commons Attribution 4.0 International License, which permits use, sharing, adaptation, distribution and reproduction in any medium or format, as long as you give appropriate credit to the original author(s) and the source, provide a link to the Creative Commons licence, and indicate if changes were made. The images or other third party material in this article are included in the article's Creative Commons licence, unless indicated otherwise in a credit line to the material. If material is not included in the article's Creative Commons licence and your intended use is not permitted by statutory regulation or exceeds the permitted use, you will need to obtain permission directly from the copyright holder. To view a copy of this licence, visit http://creativecommons.org/licenses/by/4.0/ The Creative Commons Public Domain Dedication waiver (http://creativecommons.org/publicdomain/zero/1.0/) applies to the data made available in this article, unless otherwise stated in a credit line to the data. 
Table 1 Demographic characteristics of subjects

\begin{tabular}{|c|c|c|c|c|}
\hline Parameter & StDi-1 $(n=6)$ & StDi-2 $(n=6)$ & CiDi $(n=6)$ & $P$ \\
\hline Age (years) & $68.8 \pm 11.7$ & $73.9 \pm 8.2$ & $62.8 \pm 8.0$ & 0.154 \\
\hline Female, N (\%) & $2(33.3)$ & $1(16.7)$ & $2(33.3)$ & 0.676 \\
\hline HD dur (years) & $19.2 \pm 12.3$ & $14.5 \pm 9.1$ & $19.5 \pm 4.8$ & 0.579 \\
\hline DW (Kg) & $55.9 \pm 15.3$ & $50.8 \pm 8.1$ & $56.1 \pm 8.8$ & 0.644 \\
\hline BMI $\left(\mathrm{kg} / \mathrm{m}^{2}\right)$ & $21.8 \pm 2.6$ & $22.1 \pm 3.2$ & $22.4 \pm 2.9$ & 0.418 \\
\hline Ultrafiltration (L) & $1.2 \pm 0.3$ & $1.2 \pm 0.2$ & $1.1 \pm 0.3$ & 0.734 \\
\hline WBC count $\left(10^{3} / \mu \mathrm{L}\right)$ & $5.4 \pm 1.1$ & $5.3 \pm 1.3$ & $5.8 \pm 1.2$ & 0.761 \\
\hline RBC count $\left(10^{6} \mu \mathrm{L}\right)$ & $3.5 \pm 0.3$ & $3.4 \pm 0.3$ & $3.5 \pm 0.2$ & 0.667 \\
\hline Hemoglobin (g/dL) & $12.1 \pm 0.9$ & $11.0 \pm 1.2$ & $10.8 \pm 1.9$ & 0.381 \\
\hline PLT count $\left(10^{3} / \mu \mathrm{L}\right)$ & $178 \pm 48$ & $185 \pm 14$ & $197 \pm 21$ & 0.591 \\
\hline Albumin (g/dL) & $3.4 \pm 0.2$ & $3.5 \pm 0.2$ & $3.3 \pm 0.4$ & 0.296 \\
\hline Total calcium & $9.1 \pm 0.7$ & $9.1 \pm 0.5$ & $9.3 \pm 0.7$ & 0.599 \\
\hline Total magnesium & $2.5 \pm 0.2$ & $2.3 \pm 0.3$ & $2.3 \pm 0.3$ & 0.751 \\
\hline
\end{tabular}

StDi standard dialysate, CiDi citrate dialysate, HD dur hemodialysis duration, DW dry weight, WBC white blood cell, $R B C$ red blood cell, $P L T$ platelet

concentrations are used more commonly: $1.25,1.375$, 1.5 , and $1.75 \mathrm{mmol} / \mathrm{L}$. It is assumed that the serum ionized calcium concentration eventually converges to the dialysate calcium concentration. Monitoring the postdialysis calcium concentrations may help clinicians choose and adjust the dialysate conditions to provide optimal outcomes.

Although many reports on the magnesium and calcium levels in patients undergoing HD have been published, only few have assessed the magnesium and calcium levels in on-line hemodiafiltration (OL-HDF). To the best of our knowledge, this is the first report of evaluation of magnesium and calcium levels using dialysate with a calcium concentration of $1.375 \mathrm{mmol} / \mathrm{L}$ in OL-HDF [7, 8]. This procedure is also novel in Japan, where the dialysate is prepared in a central dialysate delivery system (CDDS), and therefore, the same concentrations are administered to the patients. In contrast, in Europe, individual use is the norm and the composition of the dialysis solution administered to each patient may vary [7-10]. Moreover, the specifications of the membrane employed and albumin leakage are presented here.

Ionized magnesium and calcium comprise approximately $60 \%$ of the total serum magnesium and calcium levels [11] and indicate biological availability [12]. Here, we present the first report focused on the change of

Table 2 Dialysis prescription

\begin{tabular}{|c|c|c|c|}
\hline Parameter & StDi-1 $(n=6)$ & StDi-2 $(n=6)$ & $\mathrm{CiDi}(n=6)$ \\
\hline Blood flow rate (mL/min) & 280 & 280 & 280 \\
\hline Dialysate flow rate (mL/min) & 500 & 500 & 500 \\
\hline Effective treatment time (min) & 240 & 240 & 240 \\
\hline Filter & FIX-250S eco & FIX-250S eco & FIX-250S eco \\
\hline \multicolumn{4}{|l|}{ Dialysis solutions } \\
\hline Acetate (mmol/L) & 8 & 10.2 & - \\
\hline Citrate $(\mathrm{mmol} / \mathrm{L})$ & - & - & 0.67 \\
\hline Bicarbonate (mmol/L) & 27.5 & 25 & 35 \\
\hline Chloride (mmol/L) & 112.25 & 113 & 111 \\
\hline Glucose (mg/dL) & 125 & 100 & 150 \\
\hline Potassium (K) (mmol/L) & 2 & 2 & 2 \\
\hline Sodium (Na) (mmol/L) & 140 & 140 & 140 \\
\hline Total calcium (mmol/L) & 1.375 & 1.5 & 1.5 \\
\hline Total magnesium (mmol/L) & 0.5 & 0.5 & 0.5 \\
\hline
\end{tabular}


ionized magnesium and calcium in OL-HDF under various conditions. In this study, we aimed to clarify the influence of the dilution methods, substitution volume, and dialysate on magnesium and calcium levels in OLHDF.

\section{Methods}

This prospective study was conducted in a specialized dialysis facility in Japan (Kawashima Dialysis Clinic, Tokushima). The study was approved by the Kawashima Hospital Ethics Review Committee (No. 0302) and was conducted in accordance with the Declaration of Helsinki and the Ethical Guidelines for Medical and Health Research Involving Human Subjects. Written informed consent was obtained from every patient. The study was enrolled in the University Hospital Medical Information Network. We selected 18 stable maintenance HD patients who would be treated with OL-HDF. All vascular access was through an arteriovenous fistula and no recirculation was allowed. The patients were aged $>20$ years and had normal serum magnesium and calcium levels (1.8-2.4 and 8.4-10.0 mg/dL, respectively) prior to study initiation. During the study period, the doses of current medications containing magnesium and calcium remained unchanged. Patients with serious inflammatory symptoms and severe dysfunction of the liver, heart, and lungs were excluded. They were randomly assigned to three different dialysate groups $(n=6$ in each group). No significant differences were found among the patients' characteristics in the three dialysate groups (Table 1). The dialysate compositions for each group are presented in Table 2: two dialysate groups containing acetic acid (standard dialysate [StDi]) and one dialysate group containing citrate (citrate dialysate [CiDi]). The dialysate magnesium concentration was 0.5 $\mathrm{mmol} / \mathrm{L}$, and the dialysate calcium concentrations were 1.375 and $1.5 \mathrm{mmol} / \mathrm{L}$ for the StDi-1 and StDi-2 subgroups, respectively. There were five treatment

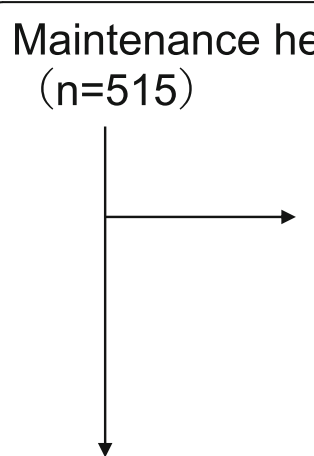

\section{Final target patients}

$(n=18)$

Exclusion $(\mathrm{n}=497)$

- Patients who do not agree to change treatment conditions for 5 weeks.

- Patients whose serum total magnesium and total calcium are outside the standard values.

- Patients who are unable to maintain a stable blood flow rate of $280 \mathrm{~mL} / \mathrm{min}$.

- Patients who are likely to change their magnesium or calcium medication during the evaluation period.

Patients with serious inflammatory symptoms and severe dysfunction of the liver, heart, and lungs were excluded.

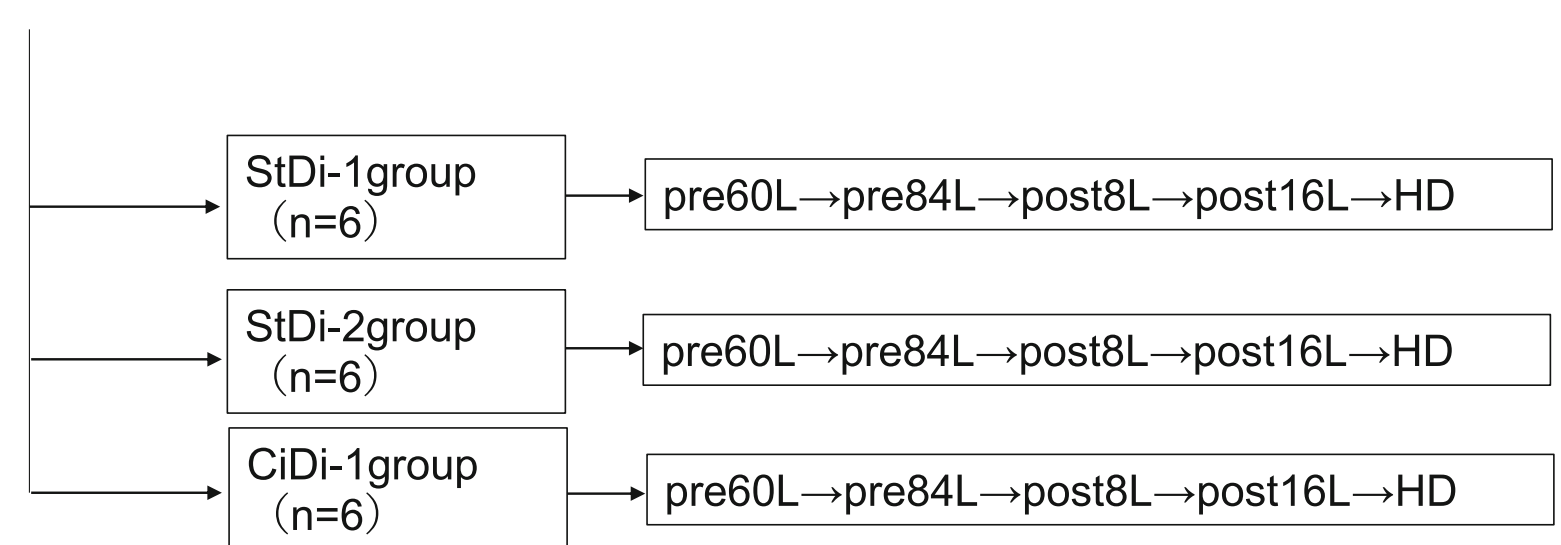

Fig. 1 Schematic flow chart depicting the study schedule. The eligible patients were divided into three groups. Each group comprised six patients (StDi-1, StDi-2, and CiDi). The evaluation days were the second and third dialysis days of each week, and five treatment conditions were applied once in each group. On evaluation days, blood samples were collected to assess the total and ionized magnesium and calcium levels in the serum before and after dialysis. HD was performed on treatment days apart from the evaluation day. StDi, standard dialysate; CiDi, citrate dialysate; HD, hemodialysis 
conditions for each dialysate group: pre-dilution OLHDF (substitution volume 60 and $84 \mathrm{~L} /$ session), postdilution OL-HDF (substitution volume 8 and $16 \mathrm{~L} /$ session), and HD. In total, 30 and 18 treatments in each dialysate and prescription group, respectively, were performed. A flow diagram of this study is presented in Fig. 1. The evaluations were conducted once for each condition, immediately after specimen collection. The first day of treatment was excluded from the evaluation because of the potential effects of water removal volume. The treatment conditions were as follows: duration, $4 \mathrm{~h}$; frequency, three times per week; blood flow rate, 280 $\mathrm{mL} / \mathrm{min}$; and total dialysate flow rate, $500 \mathrm{~mL} / \mathrm{min}$. Blood was collected before and after dialysis under each condition in front of the membrane. Pre-dialysis blood collection was performed $5 \mathrm{~min}$ after treatment initiation, and post-dialysis blood collection was performed 5 min before treatment completion. The ionized magnesium and calcium levels were immediately measured by the ion selective electrode method (Stat Profile Fox Ultra, Nova Biomedical, Waltham, MA, USA). In addition, the total magnesium and calcium levels were measured by the colorimetric method. When the serum albumin concentration was $<4.0 \mathrm{~g} / \mathrm{dL}$, we calculated the corrected calcium concentration as follows:

corrected calcium $(\mathrm{mg} / \mathrm{dL})=$ measured total calcium $(\mathrm{mg} / \mathrm{dL})+0.8(4.0-$ serum albumin $(\mathrm{g} / \mathrm{dL}))$.

The change from pre-dialysis to post-dialysis (\%) was calculated as follows: (post-dialysis concentration - predialysis concentration)/pre-dialysis concentration $\times 100$ +100 .

We also evaluated the removed amount of magnesium and calcium as well as the albumin leakage using the partial storage method for the spent dialysate. In this method, the drained dialysate was extracted at a rate of $0.9 \mathrm{~L} / \mathrm{h}$ using a multi-roller pump (MF-01; JMS Corp., Hiroshima, Japan) and was stored for $4 \mathrm{~h}$. At our hospital, we observed that there was no significant difference between the measurement errors after performing the total and partial storage methods.

All data were expressed as means \pm standard deviations (SDs). Statistical analyses were performed using a repeated-measures analysis of variance, one-way analysis

Table 3 Total and ionized concentrations of magnesium and calcium according to treatment conditions in group StDi-1

\begin{tabular}{|c|c|c|c|c|c|c|}
\hline \multirow{2}{*}{$\begin{array}{l}\text { Substitution volume [L/ } \\
\text { session] }\end{array}$} & \multicolumn{2}{|l|}{ Pre-dilution } & \multicolumn{2}{|c|}{ Post-dilution } & \multirow{2}{*}{$\begin{array}{l}\mathrm{HD}(n= \\
6)\end{array}$} & \multirow{2}{*}{$\begin{array}{l}P(5 \\
\text { groups) }\end{array}$} \\
\hline & $60(n=6)$ & $84(n=6)$ & $8(n=6)$ & $16(n=6)$ & & \\
\hline \multicolumn{7}{|l|}{ Pre-dialysis values } \\
\hline Total magnesium (mg/dL) & $2.60 \pm 0.12$ & $2.50 \pm 0.10$ & $2.58 \pm 0.13$ & $2.50 \pm 0.20$ & $2.54 \pm 0.23$ & 0.817 \\
\hline lonized magnesium (mmol/L) & $0.64 \pm 0.03$ & $0.59 \pm 0.03$ & $0.62 \pm 0.04$ & $0.60 \pm 0.04$ & $0.59 \pm 0.03$ & 0.146 \\
\hline Total calcium (mg/dL) & $8.96 \pm 0.76$ & $9.22 \pm 0.78$ & $9.16 \pm 0.62$ & $9.18 \pm 0.76$ & $9.02 \pm 0.79$ & 0.981 \\
\hline lonized calcium (mmol/L) & $1.16 \pm 0.09$ & $1.15 \pm 0.08$ & $1.17 \pm 0.06$ & $1.14 \pm 0.07$ & $1.12 \pm 0.11$ & 0.926 \\
\hline $\mathrm{pH}$ & $7.38 \pm 0.03$ & $7.40 \pm 0.03$ & $7.40 \pm 0.02$ & $7.38 \pm 0.03$ & $7.39 \pm 0.04$ & 0.861 \\
\hline \multicolumn{7}{|l|}{ Post-dialysis values } \\
\hline Total magnesium (mg/dL) & $1.98 \pm 0.11$ & $2.04 \pm 0.13$ & $1.98 \pm 0.13$ & $1.88 \pm 0.11$ & $1.98 \pm 0.04$ & 0.283 \\
\hline lonized magnesium (mmol/L) & $0.48 \pm 0.06$ & $0.47 \pm 0.06$ & $0.45 \pm 0.06$ & $0.47 \pm 0.04$ & $0.48 \pm 0.05$ & 0.229 \\
\hline Total calcium (mg/dL) & $9.08 \pm 0.28$ & $8.96 \pm 0.25$ & $9.18 \pm 0.17$ & $9.10 \pm 0.22$ & $9.12 \pm 0.28$ & 0.705 \\
\hline lonized calcium (mmol/L) & $1.20 \pm 0.02$ & $1.19 \pm 0.03$ & $1.16 \pm 0.05$ & $1.18 \pm 0.03$ & $1.19 \pm 0.03$ & 0.524 \\
\hline $\mathrm{pH}$ & $7.42 \pm 0.01$ & $7.41 \pm 0.03$ & $7.42 \pm 0.03$ & $7.41 \pm 0.02$ & $7.41 \pm 0.02$ & 0.951 \\
\hline \multicolumn{7}{|l|}{ Pre-dialysis to post-dialysis } \\
\hline Total magnesium (\%) & $76.3 \pm 6.3$ & $81.6 \pm 4.5$ & $76.9 \pm 7.0$ & $75.5 \pm 5.4$ & $78.4 \pm 7.0$ & 0.551 \\
\hline lonized magnesium (\%) & $75.3 \pm 7.6$ & $80.6 \pm 10.2$ & $72.6 \pm 8.3$ & $80.0 \pm 9.1$ & $81.9 \pm 11.5$ & 0.496 \\
\hline Total calcium (\%) & $101.5 \pm 6.1$ & $97.6 \pm 5.9$ & $100.5 \pm 5.4$ & $99.6 \pm 7.5$ & $101.5 \pm 6.2$ & 0.843 \\
\hline Ionized calcium (\%) & $103.8 \pm 6.3$ & $104.0 \pm 5.2$ & $99.5 \pm 6.5$ & $104.5 \pm 5.2$ & $106.4 \pm 9.2$ & 0.586 \\
\hline $\mathrm{pH}$ & $100.4 \pm 0.3$ & $100.2 \pm 0.5$ & $100.2 \pm 0.3$ & $100.3 \pm 0.4$ & $100.3 \pm 0.3$ & 0.827 \\
\hline \multicolumn{7}{|l|}{ Removal amount } \\
\hline Magnesium (mg) & $129 \pm 97$ & $126 \pm 57$ & $102 \pm 72$ & $128 \pm 107$ & $129 \pm 55$ & 0.979 \\
\hline Calcium (mg) & $472 \pm 176$ & $385 \pm 183$ & $362 \pm 126$ & $343 \pm 152$ & $470 \pm 181$ & 0.615 \\
\hline Albumin leakage (g/session) & $3.5 \pm 0.6$ & $3.0 \pm 0.3$ & $4.3 \pm 0.7$ & $5.5 \pm 0.7$ & $3.0 \pm 0.4$ & $<0.001$ \\
\hline
\end{tabular}


of variance, and a paired t-test using SPSS statistics ver. 23 (IBM Corp., Armonk, NY, USA). The chi-square and Fisher's exact tests were used to compare the categorical variables. Values of $\mathrm{p}<0.05$ were considered statistically significant.

\section{Results}

Effect of dialysis parameters on magnesium and calcium serum concentration

To determine the influence of the five dialysis treatment parameters on the magnesium and calcium levels, we compared the post-dialysis levels of ionized and total serum levels of each group $(n=6$ in each group). Tables 3, 4, and 5 summarize the magnesium and calcium levels for the StDi and CiDi dialysate groups. The data indicated that the dilution methods and the substitution volume did not affect the total or ionized magnesium and calcium serum concentrations after dialysis. Furthermore, $\mathrm{pH}$ did not differ between the five dialysis treatments.

Although the albumin leakage was approximately $3 \mathrm{~g} /$ session in the pre-dilution and HD methods and tended to increase to approximately $4-5 \mathrm{~g} /$ session in the postdilution method, the magnesium and calcium removal levels did not differ between the five dialysis treatments.

\section{Effect of dialysate on magnesium serum concentration}

Figures 2 and 3 present the total and ionized magnesium pre- and post-dialysis concentrations during the five treatment conditions, respectively $(n=6$ in each group). The obtained data showed that the predialysis ionized magnesium levels in the $\mathrm{CiDi}$ group were significantly lower than those of the StDi-1 group $(p<0.001)$. There was no significant difference in the total magnesium concentrations at postdialysis, but the ionized magnesium concentrations at post-dialysis in the $\mathrm{CiDi}$ group were lower than those of the StDi-1 and StDi-2 groups $(p<0.001)$. The total and ionized magnesium levels were significantly decreased by dialysis after all three dialysate treatments $(p<0.001)$.

There was no difference in the magnesium removal levels after the three dialysate treatments (Fig. 4).

Table 4 Total and ionized concentrations of magnesium and calcium according to treatment conditions in group StDi-2

\begin{tabular}{|c|c|c|c|c|c|c|}
\hline \multirow{2}{*}{$\begin{array}{l}\text { Substitution volume [L/ } \\
\text { session] }\end{array}$} & \multicolumn{2}{|l|}{ Pre-dilution } & \multicolumn{2}{|c|}{ Post-dilution } & \multirow{2}{*}{$\begin{array}{l}H D(n= \\
6)\end{array}$} & \multirow{2}{*}{$\begin{array}{l}\mathrm{P} \text { (5 } \\
\text { groups) }\end{array}$} \\
\hline & $60(n=6)$ & $84(n=6)$ & $8(n=6)$ & $16(n=6)$ & & \\
\hline \multicolumn{7}{|l|}{ Pre-dialysis values } \\
\hline Total magnesium (mg/dL) & $2.30 \pm 0.35$ & $2.27 \pm 0.30$ & $2.33 \pm 0.32$ & $2.22 \pm 0.30$ & $2.30 \pm 0.28$ & 0.983 \\
\hline lonized magnesium (mmol/L) & $0.61 \pm 0.10$ & $0.56 \pm 0.04$ & $0.55 \pm 0.06$ & $0.53 \pm 0.05$ & $0.57 \pm 0.05$ & 0.545 \\
\hline Total calcium (mg/dL) & $9.08 \pm 0.72$ & $8.98 \pm 0.65$ & $8.95 \pm 0.45$ & $9.12 \pm 0.47$ & $9.13 \pm 0.41$ & 0.969 \\
\hline lonized calcium (mmol/L) & $1.16 \pm 0.08$ & $1.16 \pm 0.11$ & $1.14 \pm 0.07$ & $1.15 \pm 0.07$ & $1.16 \pm 0.05$ & 0.992 \\
\hline $\mathrm{pH}$ & $7.38 \pm 0.03$ & $7.38 \pm 0.01$ & $7.38 \pm 0.03$ & $7.38 \pm 0.02$ & $7.38 \pm 0.02$ & 0.591 \\
\hline \multicolumn{7}{|l|}{ Post-dialysis values } \\
\hline Total magnesium (mg/dL) & $1.93 \pm 0.14$ & $1.95 \pm 0.16$ & $2.00 \pm 0.15$ & $1.95 \pm 0.10$ & $1.93 \pm 0.12$ & 0.911 \\
\hline lonized magnesium (mmol/L) & $0.45 \pm 0.05$ & $0.44 \pm 0.03$ & $0.49 \pm 0.02$ & $0.43 \pm 0.04$ & $0.46 \pm 0.02$ & 0.166 \\
\hline Total calcium (mg/dL) & $9.92 \pm 0.23$ & $9.70 \pm 0.18$ & $10.0 \pm 0.22$ & $10.0 \pm 0.25$ & $9.95 \pm 0.20$ & 0.113 \\
\hline lonized calcium (mmol/L) & $1.27 \pm 0.06$ & $1.21 \pm 0.07$ & $1.28 \pm 0.02$ & $1.27 \pm 0.07$ & $1.25 \pm 0.04$ & 0.207 \\
\hline $\mathrm{pH}$ & $7.41 \pm 0.03$ & $7.41 \pm 0.03$ & $7.42 \pm 0.03$ & $7.41 \pm 0.02$ & $7.41 \pm 0.02$ & 0.790 \\
\hline \multicolumn{7}{|l|}{ Pre-dialysis to post-dialysis } \\
\hline Total magnesium (\%) & $85.1 \pm 9.2$ & $86.6 \pm 6.2$ & $86.4 \pm 6.7$ & $87.2 \pm 7.9$ & $84.6 \pm 5.6$ & 0.967 \\
\hline lonized magnesium (\%) & $73.9 \pm 7.3$ & $79.1 \pm 11.8$ & $79.3 \pm 7.9$ & $78.4 \pm 8.3$ & $81.3 \pm 9.5$ & 0.373 \\
\hline Total calcium (\%) & $109.0 \pm 7.9$ & $108.4 \pm 6.9$ & $111.9 \pm 4.0$ & $110.1 \pm 5.8$ & $109.1 \pm 4.1$ & 0.878 \\
\hline Ionized calcium (\%) & $109.8 \pm 6.7$ & $105.8 \pm 4.4$ & $112.8 \pm 7.0$ & $109.2 \pm 2.5$ & $107.5 \pm 6.7$ & 0.672 \\
\hline $\mathrm{pH}$ & $100.3 \pm 0.4$ & $100.5 \pm 0.4$ & $100.6 \pm 0.5$ & $100.4 \pm 0.3$ & $100.4 \pm 0.3$ & 0.750 \\
\hline \multicolumn{7}{|l|}{ Removal amount } \\
\hline Magnesium (mg) & $90 \pm 95$ & $67 \pm 62$ & $43 \pm 72$ & $128 \pm 91$ & $87 \pm 94$ & 0.513 \\
\hline Calcium (mg) & $196 \pm 154$ & $81 \pm 85$ & $187 \pm 160$ & $204 \pm 90$ & $202 \pm 113$ & 0.397 \\
\hline Albumin leakage (g/session) & $3.1 \pm 1.2$ & $3.0 \pm 0.4$ & $4.3 \pm 0.9$ & $5.2 \pm 0.9$ & $2.8 \pm 0.5$ & $<0.001$ \\
\hline
\end{tabular}


Table 5 Total and ionized concentrations of magnesium and calcium according to treatment conditions in group CiDi

\begin{tabular}{|c|c|c|c|c|c|c|}
\hline \multirow{2}{*}{$\begin{array}{l}\text { Substitution volume [L/ } \\
\text { session] }\end{array}$} & \multicolumn{2}{|l|}{ Pre-dilution } & \multicolumn{2}{|c|}{ Post-dilution } & \multirow{2}{*}{$\begin{array}{l}\mathrm{HD}(n= \\
6)\end{array}$} & \multirow{2}{*}{$\begin{array}{l}P(5 \\
\text { groups) }\end{array}$} \\
\hline & $60(n=6)$ & $84(n=6)$ & $8(n=6)$ & $16(n=6)$ & & \\
\hline \multicolumn{7}{|l|}{ Pre-dialysis values } \\
\hline Total magnesium (mg/dL) & $2.32 \pm 0.37$ & $2.32 \pm 0.35$ & $2.27 \pm 0.33$ & $2.25 \pm 0.32$ & $2.32 \pm 0.39$ & 0.995 \\
\hline Ionized magnesium (mmol/L) & $0.53 \pm 0.05$ & $0.52 \pm 0.06$ & $0.52 \pm 0.04$ & $0.53 \pm 0.05$ & $0.52 \pm 0.06$ & 0.994 \\
\hline Total calcium (mg/dL) & $9.33 \pm 0.76$ & $9.27 \pm 0.83$ & $9.23 \pm 0.54$ & $9.35 \pm 0.71$ & $9.12 \pm 0.59$ & 0.979 \\
\hline lonized calcium (mmol/L) & $1.13 \pm 0.05$ & $1.15 \pm 0.06$ & $1.11 \pm 0.07$ & $1.17 \pm 0.06$ & $1.14 \pm 0.05$ & 0.588 \\
\hline $\mathrm{pH}$ & $7.40 \pm 0.02$ & $7.39 \pm 0.02$ & $7.39 \pm 0.03$ & $7.40 \pm 0.02$ & $7.40 \pm 0.02$ & 7.848 \\
\hline \multicolumn{7}{|l|}{ Post-dialysis values } \\
\hline Total magnesium (mg/dL) & $1.92 \pm 0.10$ & $1.97 \pm 0.12$ & $1.85 \pm 0.14$ & $1.92 \pm 0.12$ & $1.92 \pm 0.19$ & 0.488 \\
\hline lonized magnesium (mmol/L) & $0.39 \pm 0.05$ & $0.40 \pm 0.04$ & $0.38 \pm 0.05$ & $0.39 \pm 0.04$ & $0.40 \pm 0.04$ & 0.956 \\
\hline Total calcium (mg/dL) & $9.60 \pm 0.20$ & $9.62 \pm 0.36$ & $9.65 \pm 0.19$ & $9.67 \pm 0.31$ & $9.45 \pm 0.19$ & 0.437 \\
\hline lonized calcium (mmol/L) & $1.14 \pm 0.02$ & $1.14 \pm 0.01$ & $1.13 \pm 0.03$ & $1.14 \pm 0.03$ & $1.13 \pm 0.03$ & 0.868 \\
\hline $\mathrm{pH}$ & $7.46 \pm 0.01$ & $7.46 \pm 0.01$ & $7.45 \pm 0.01$ & $7.47 \pm 0.02$ & $7.47 \pm 0.02$ & 0.557 \\
\hline \multicolumn{7}{|l|}{ Pre-dialysis to post-dialysis } \\
\hline Total magnesium (\%) & $83.8 \pm 8.4$ & $86.0 \pm 9.4$ & $82.4 \pm 6.9$ & $86.1 \pm 8.1$ & $83.8 \pm 9.1$ & 0.928 \\
\hline lonized magnesium (\%) & $74.9 \pm 7.7$ & $75.6 \pm 9.0$ & $73.8 \pm 10.3$ & $73.3 \pm 9.8$ & $78.3 \pm 10.2$ & 0.904 \\
\hline Total calcium (\%) & $103.3 \pm 6.1$ & $104.2 \pm 5.7$ & $104.7 \pm 5.0$ & $103.7 \pm 4.6$ & $103.9 \pm 5.1$ & 0.999 \\
\hline lonized calcium (\%) & $100.8 \pm 4.6$ & $99.4 \pm 4.1$ & $101.9 \pm 4.4$ & $98.1 \pm 5.7$ & $99.3 \pm 5.6$ & 0.717 \\
\hline $\mathrm{pH}$ & $100.9 \pm 0.2$ & $100.9 \pm 0.2$ & $100.9 \pm 0.3$ & $100.9 \pm 0.2$ & $101.0 \pm 0.5$ & 0.988 \\
\hline \multicolumn{7}{|l|}{ Removal amount } \\
\hline Magnesium (mg) & $104 \pm 80$ & $113 \pm 87$ & $37 \pm 68$ & $120 \pm 50$ & $141 \pm 63$ & 0.192 \\
\hline Calcium (mg) & $294 \pm 210$ & $222 \pm 107$ & $267 \pm 134$ & $294 \pm 199$ & $217 \pm 115$ & 0.941 \\
\hline Albumin leakage (g/session) & $3.1 \pm 0.3$ & $3.3 \pm 0.3$ & $4.9 \pm 0.7$ & $5.1 \pm 0.9$ & $3.2 \pm 0.5$ & 0.003 \\
\hline
\end{tabular}

\section{Effect of dialysate on calcium serum concentration}

Figures 5 and 6 present the total and ionized calcium preand post-dialysis concentrations during the five treatment conditions, respectively ( $\mathrm{n}=6$ in each group). There was no significant difference in the total and ionized calcium concentrations at pre-dialysis. The total and ionized calcium concentrations at post-dialysis in the StDi-2 group were higher than those of the StDi- 1 and CiDi groups $(p<$ $0.001)$. The total and ionized calcium concentrations were significantly increased by dialysis in the StDi- 2 group after treatment $(p<0.001)$.

The calcium removal amount was higher in the StDi-1 than in the StDi-2 group ( $<0.05)$ (Fig. 4).

\section{Discussion}

To the best of our knowledge, this is the first report showing that three different dialysis solutions, each with a different calcium concentration, were used in CDDS and that the method of dilution and the amounts of the replacement solution have little effect on the ionized magnesium and calcium concentrations. A previous study showed that there was no correlation between the total and ionized magnesium serum concentrations [13]. Therefore, we investigated the changes in the total and ionized magnesium levels. OL-HDF is a treatment method that utilizes a large volume of replacement fluid, leading to concerns about the possibility of significant electrolyte fluctuation. Particularly, in post-dilution OLHDF, which is the mainstream treatment method in Europe, a large volume of replacement fluid flows directly into the body after passing through the membrane [14-16]. We hypothesized that with increased albumin leakage, albumin-bound magnesium and calcium are removed in post-dilution OL-HDF. Albumin leakage is analyzed by a combination of the membrane used, the dilution method, and the volume of replacement fluid. However, European OL-HDF assessments do not specify the membrane pore size or the requirement of solute removal [14-16]. Similarly, existing reports do not provide detailed specifications of the membrane or solute removal; thus, the effect of albumin leakage is unknown [7-10]. Regarding the effect of albumin leakage into the dialysate on calcium delivery, each gram of leaking albumin is considered to remove approximately $1 \mathrm{mg}$ of 


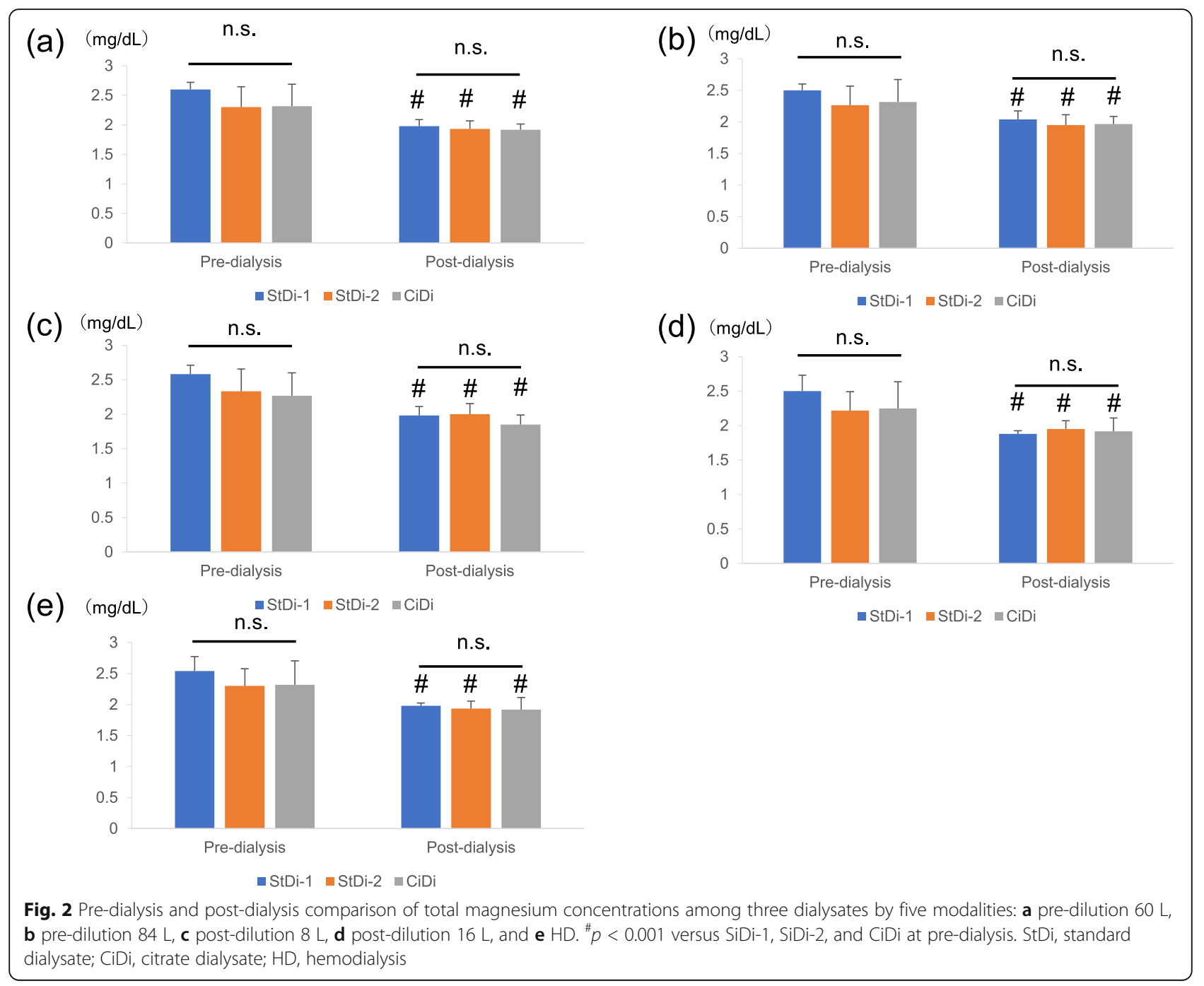

calcium [17]. Therefore, the effect of albumin leakage on calcium delivery is considered to be small; nevertheless, the effect on magnesium delivery remains unknown. Although they are both divalent cations, the effect of albumin leakage on magnesium and calcium may be different; therefore, we examined their relationships with albumin leakage. Interestingly, we found no difference in the amount of magnesium and calcium removed or in the values of ionized magnesium and calcium in the blood when albumin leakage increased with OL-HDF after dilution. Furthermore, the albumin leakage in the membrane we employed was well defined. Given that the membrane used in this study did not cause excessive transmembrane pressure or significant albumin leakage [18], our results indicated that post-dilution OL-HDF does not significantly impact the concentration of ionized magnesium and calcium when albumin leakage is limited to approximately $5 \mathrm{~g} / \mathrm{session}$.
We further investigated the magnesium and calcium concentrations with different dialysates. Although the post-dialysis total magnesium concentration did not differ between dialysates, the ionized magnesium levels were significantly reduced in the $\mathrm{CiDi}$ group compared to those in the StDi-1 and StDi-2 groups. As ionized magnesium is removed by diffusion, the post-dialysis levels should be consistent with the dialysate concentration $(0.5 \mathrm{mmol} / \mathrm{L})$. The amount of removed magnesium was not significantly different but tended to be lower in the StDi-2 group. However, the value of ionized magnesium was lower in the StDi-2 than in the StDi-1 group. The lack of association between the results of removal amount and blood values differed from that of calcium, suggesting that magnesium and calcium may have different dynamics in the body. Particularly, some patients receiving CiDi had ionized magnesium concentrations < $0.45 \mathrm{mmol} / \mathrm{L}$, which may be attributed to chelation of 


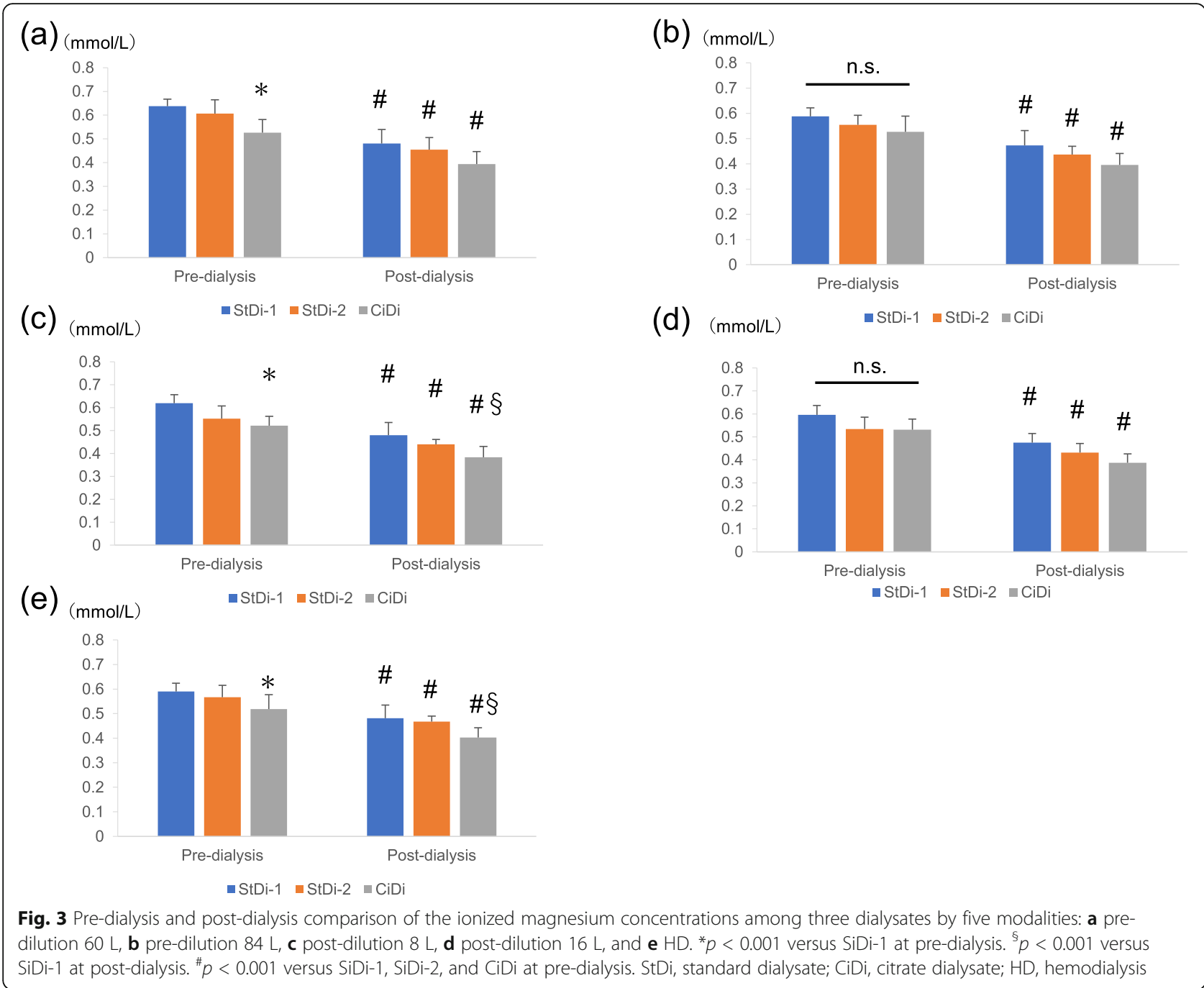

citric acid and $\mathrm{Mg}^{2+}$ in the dialysate [19], thus resulting in lower than theoretical ionized magnesium levels in the dialysate, which in turn results in the removal of ionized magnesium from the blood. However, the amount of magnesium removal was not significantly higher in the CiDi group. It is also important to note that we cannot predict the decrease in ionized magnesium from the removed amount. This finding suggested that we should be cautious when using $\mathrm{CiDi}$ to prevent increased risks of lethal arrhythmia and cardiovascular mortality from hypomagnesemia. In addition, since the total magnesium levels in all the pre-dialysates were $<2.7 \mathrm{mg} / \mathrm{dL}$, we should reconsider the magnesium concentration in the dialysate.

Regarding calcium, the results seemed to be related to the removal amount: as the dialysate calcium concentration in the StDi-2 group was high $(1.5 \mathrm{mmol} / \mathrm{L})$, the total and ionized calcium concentrations after treatment were higher in the StDi-2 group, and the removal amount at that time was also low. However, the patients in the CiDi group, whose dialysate calcium concentration was also $1.5 \mathrm{mmol} / \mathrm{L}$, showed a tendency different from those in the StDi-2 group. Although the total calcium concentration increased in the $\mathrm{CiDi}$ group, the ionized calcium concentration remained unchanged before and after dialysis and was significantly lower than the StDi-2 ionized calcium concentration. In line with the aforementioned results for ionized magnesium in the $\mathrm{CiDi}$ treatment group, citric acid likely formed a chelate complex with ionized calcium, thus leading to a reduced number of free calcium ions in the serum. In addition, in bicarbonate $\mathrm{HD}$, calcium mass balance tests showed positive calcium transfer from dialysate to blood at a concentration of $1.5 \mathrm{mmol} / \mathrm{L}$, whereas at $1.25 \mathrm{mmol} / \mathrm{L}$, most patients 


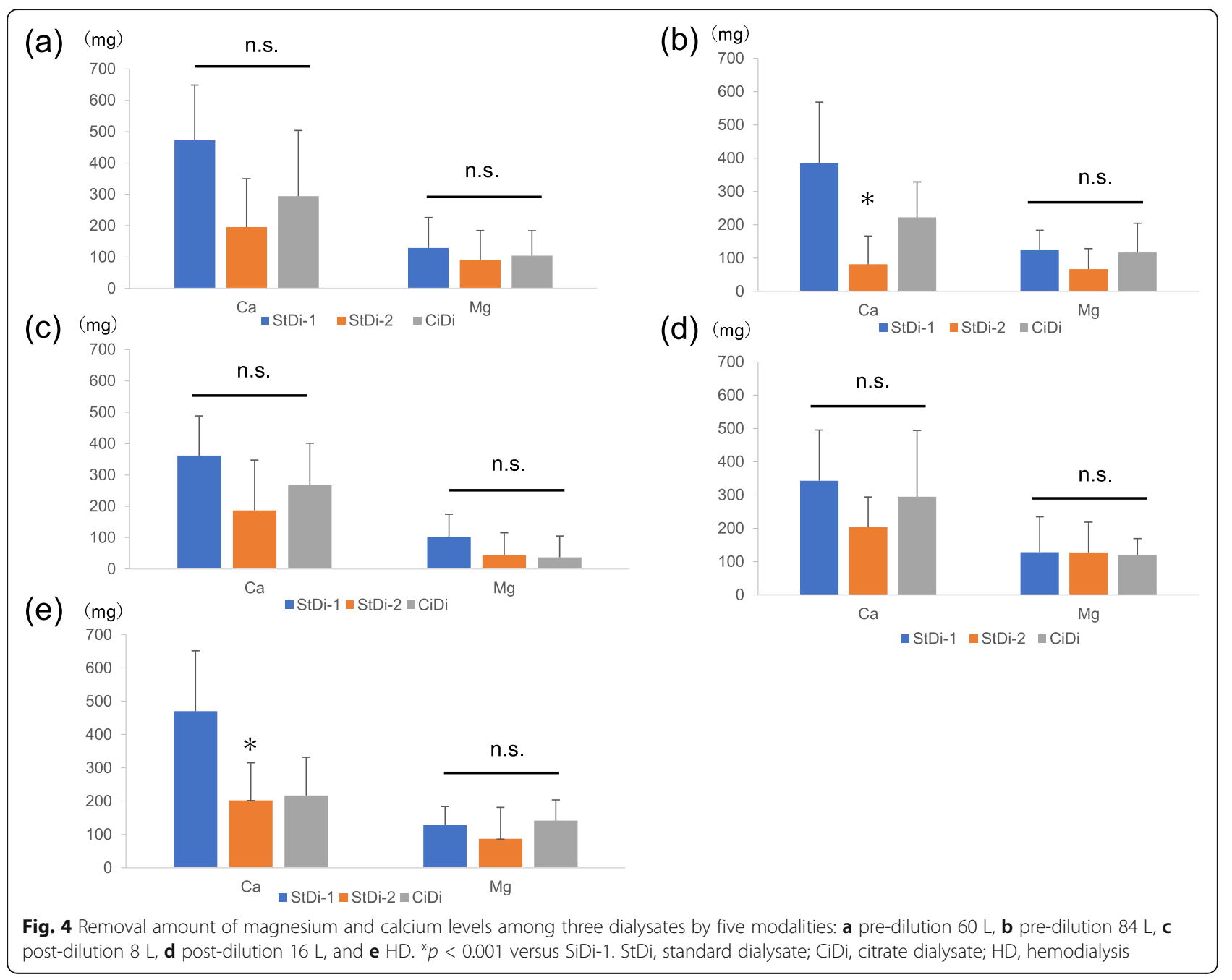

displayed an almost neutral or slightly negative calcium transfer [20]. Therefore, the evaluation at the intermediate value of $1.375 \mathrm{mmol} / \mathrm{L}$ is critically important.

Although magnesium and calcium are divalent cations, the rates of change of the concentrations of ionized magnesium and calcium between dialysates were distinct. A previous study indicated that the ionized magnesium and calcium concentrations are affected by several factors, including the $\mathrm{pH}$ and the bicarbonate ion concentration [11]. However, as this was a crossover study in the same patients, we hypothesized that the effects of $\mathrm{pH}$ and bicarbonate ions on the ionized magnesium and calcium concentrations should are equivalent. Therefore, we considered that the chelation kinetics in the body may be significantly different for $\mathrm{Mg}^{2+}$ compared to $\mathrm{Ca}^{2+}[21]$.

Our study had several potential limitations. First, the ionized magnesium and calcium levels were measured before the membrane only. It is possible that homeostasis in the body overcomes the dilution methods and the replacement volume, resulting in a lack of differences between the methods. Future studies should also measure the ionized magnesium and calcium concentrations after the membrane to investigate changes in either side of the membrane. Second, our study collected shortterm data only. Further studies are needed to investigate the effects of the same dialysate on the concentrations of magnesium and calcium for a longer period of time. Third, the sample size was considerably small; therefore, the detection power of the analysis would not produce sufficient statistically relevant values. However, from a practical point of view, it is difficult to further increase the sample size. Other parameters examined herein that did not show substantial variations may appear as significant statistical differences when a larger sample size is used.

\section{Conclusions}

In this study, when using acetate-based dialysate, we observed no difference among the five investigated 


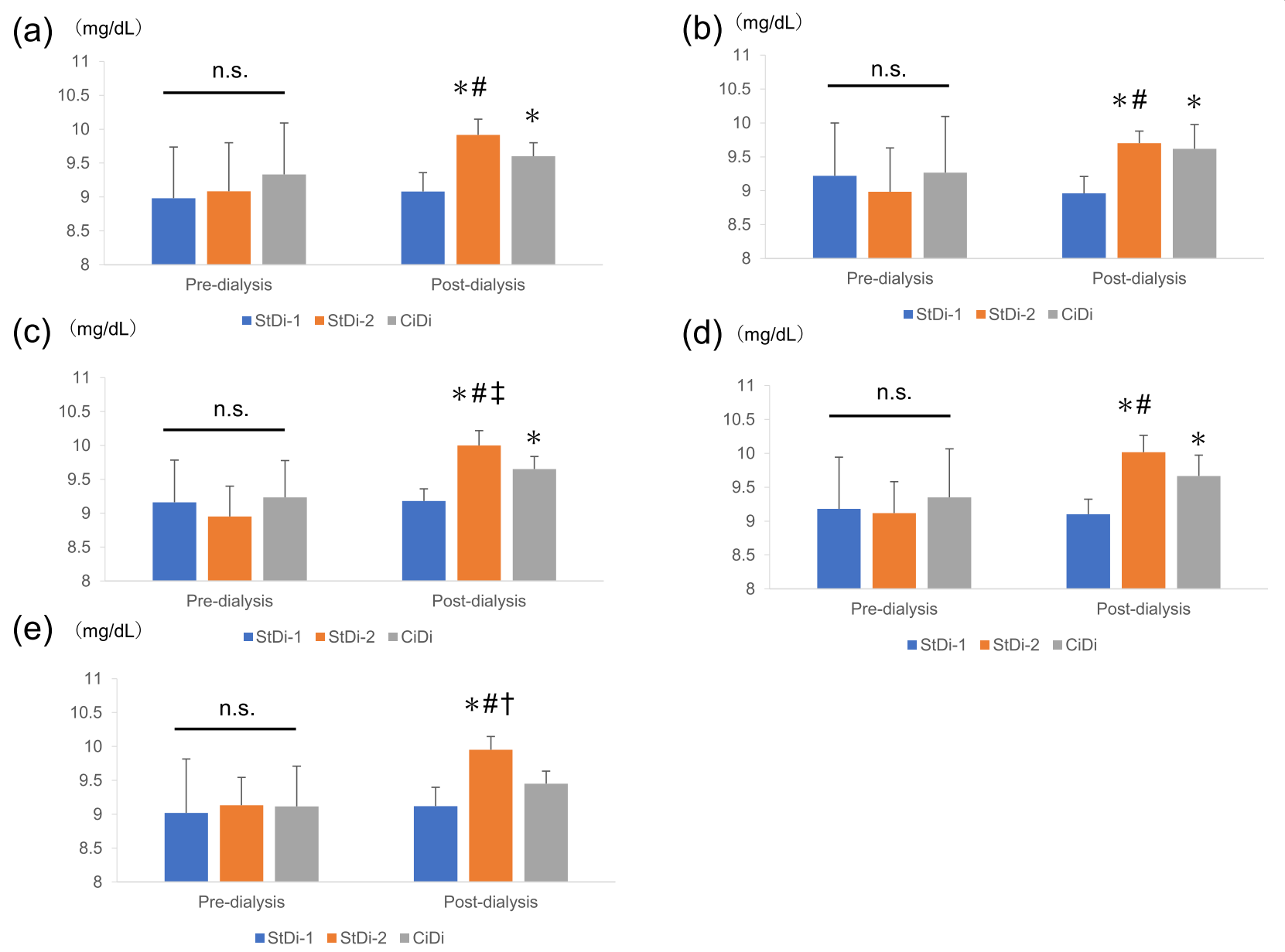

Fig. 5 Pre-dialysis and post-dialysis comparison of total calcium concentrations among three dialysates by five modalities: a pre-dilution $60 \mathrm{~L}$, $\mathbf{b}$ pre-dilution $84 \mathrm{~L}$, c post-dilution $8 \mathrm{~L}$, d post-dilution $16 \mathrm{~L}$, and e HD. ${ }^{*} p<0.001$ versus SiDi- 1 at post-dialysis, ${ }^{\neq} p<0.05$ versus CiDi at post-dialysis, ${ }^{+} p<0.001$ versus CiDi at post-dialysis. ${ }^{\#} p<0.001$ versus SiDi-2 at pre-dialysis. StDi, standard dialysate; CiDi, citrate dialysate; HD, hemodialysis 


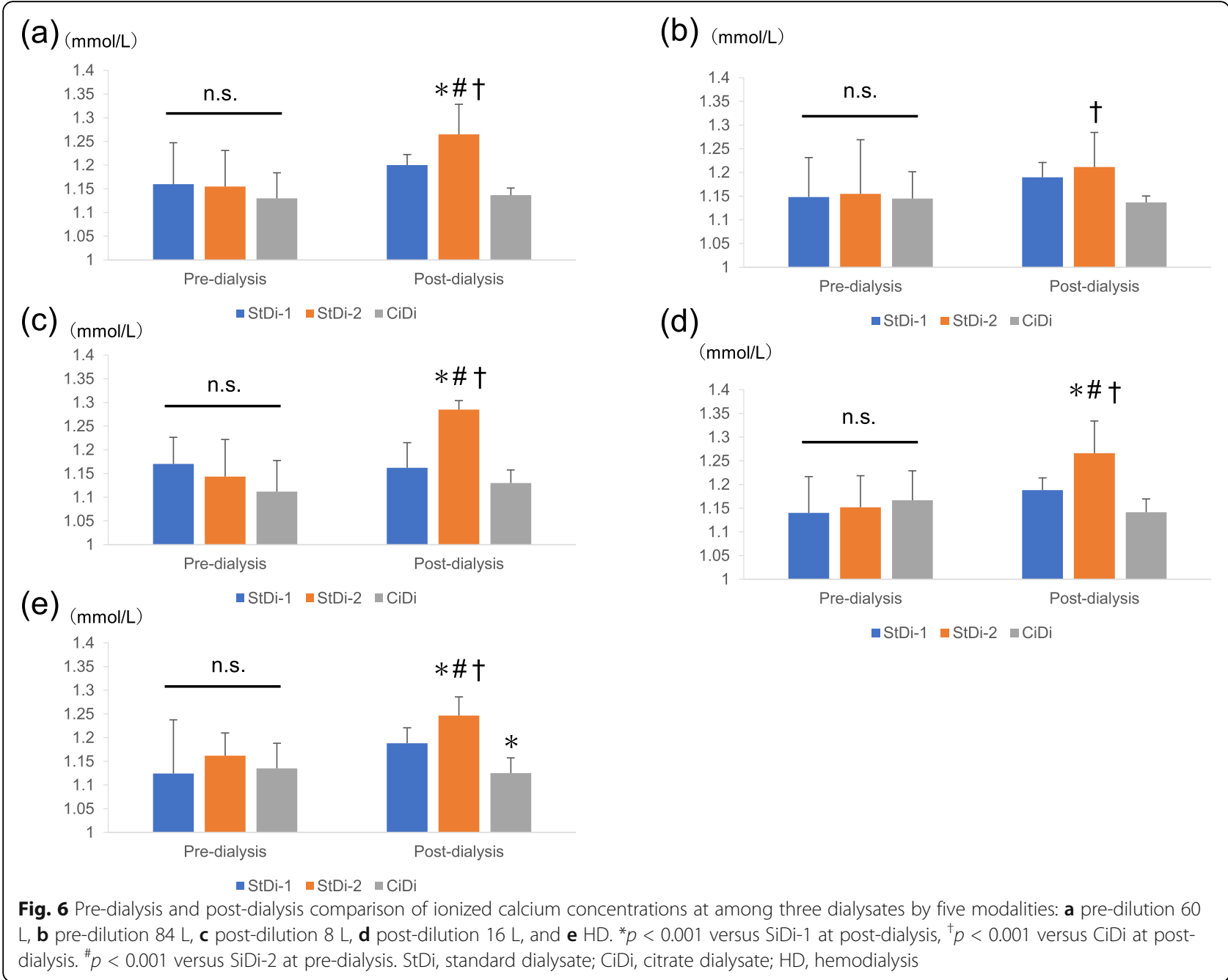

conditions of dialysis (i.e., hemodiafiltration with pre-or post-dilution, hemodiafiltration with higher or lower volume of substitution fluids, and HD) in post-dialysis ionized serum magnesium or calcium concentrations. However, when dialysate containing citric acid is used, the post-dialysis serum concentration of ionized magnesium may fall to a level below the corresponding concentration in the dialysate containing citric acid, possibly because of chelation of $\mathrm{Mg}^{2+}$ by citric acid. It is necessary to evaluate the relationship between the dialysate and mortality in the future.

\section{Abbreviations}

StDi: Standard dialysate; CiDi: Citrate dialysate; HD: Hemodialysis; OLHDF: On-line hemodiafiltration; CDDS: Central dialysate delivery system

\section{Acknowledgements}

We would like to thank Tomohiro Nakamura (Department of Preventive Medicine and Epidemiology, Tohoku University, Tohoku Medical Megabank Organization) for his aid with the statistical analyses. We also thank Koichi Kikuchi and Takaaki Abe (Division of Nephrology, Endocrinology, and Vascular Medicine, Tohoku University Graduate School of Medicine) for valuable discussion. We thank Editage for their technical assistance in editing a draft of this manuscript.

\section{Authors' contributions}

YT designed the study, performed the data analysis, and wrote the manuscript. YT, RH, DO, and HM collected the clinical data. The authors read and approved the final manuscript.

\section{Funding}

There was no funding for the current study.

\section{Availability of data and materials}

All data generated or analyzed during this study are included in this published article.

\section{Declarations}

\section{Ethics approval and consent to participate}

This research was approved by the ethical committee of Kawashima Hospital (approval number, 0302). The original data were totally anonymized, and therefore, there were no risks to the privacy of patients. The data presented in the current manuscript did not contain any images, videos, or voice recording, which might have a risk for identifying an individual.

\section{Consent for publication}

Not applicable. 


\section{Competing interests}

The authors declare that they have no competing interests.

\section{Author details}

'Clinical Engineering Department of Kawashima Hospital, 1-39 Kitasakoichiban-cho, Tokushima, Tokushima 770-0011, Japan. ${ }^{2}$ Department of Kidney Disease, Kawashima Hospital, 1-39 Kitasakoichiban-cho, Tokushima, Tokushima 770-0011, Japan. ${ }^{3}$ Department of Cardiovascular Surgery, Kawashima Hospital, 1-39 Kitasakoichiban-cho, Tokushima 770-0011, Japan.

Received: 28 December 2020 Accepted: 11 May 2021

Published online: 27 May 2021

\section{References}

1. Cunningham J, Rodriguez M, Messa P. Magnesium in chronic kidney disease stages 3 and 4 and in dialysis patients. Clin Kidney J. 2012;5(Suppl 1):i39-51. https://doi.org/10.1093/ndtplus/sfr166.

2. Leenders NHJ, van Ittersum FJ, Hoekstra T, Hoenderop JGJ, Vervloet MG. Routine hemodialysis induces a decline in plasma magnesium concentration in most patients: a prospective observational cohort study. Sci Rep. 2018;8(1):10256. https://doi.org/10.1038/s41598-018-28629-X.

3. Sakaguchi Y, Fujii N, Shoji T, Hayashi T, Rakugi H, Isaka Y. Hypomagnesemia is a significant predictor of cardiovascular and non-cardiovascular mortality in patients undergoing hemodialysis. Kidney Int. 2014;85(1):174-81. https:// doi.org/10.1038/ki.2013.327.

4. Sakaguchi Y, Fujii N, Shoji T, Hayashi T, Rakugi H, Iseki K, et al. Magnesium modifies the cardiovascular mortality risk associated with hyperphosphatemia in patients undergoing hemodialysis: a cohort study. PLoS One. 2014;9(12):e1 16273. https://doi.org/10.1371/journal.pone.0116273.

5. Guerin AP, London GM, Marchais SJ, Metivier F. Arterial stiffening and vascular calcifications in end-stage renal disease. Nephrol Dial Transplant. 2000;15(7):1014-21. https://doi.org/10.1093/ndt/15.7.1014.

6. Goodman WG, Goldin J, Kuizon BD, Yoon C, Gales B, Sider D, et al. Coronary-artery calcification in young adults with end-stage renal disease who are undergoing dialysis. N Engl J Med. 2000;342(20):1478-83. https:// doi.org/10.1056/NEJM200005183422003.

7. Nuñez MM, de Alarcón R, Roca S, Álvarez G, Ros MS, Jimeno C, et al. Citrate versus acetate-based dialysate in on-line haemodiafiltration. a prospective cross-over study. Blood Purif. 2015;39(1-3):181-7. https://doi.org/10.1159/ 000371569.

8. Grundström G, Christensson A, Alquist M, Nilsson LG, Segelmark M. Replacement of acetate with citrate in dialysis fluid: a randomized clinical trial of short term safety and fluid biocompatibility. BMC Nephrol. 2013; 14(1):216. https://doi.org/10.1186/1471-2369-14-216.

9. Šafránek R, Moučka P, Vávrová J, Palička V, Pavlíková L, Sulková SD. Changes of serum calcium, magnesium and parathyroid hormone induced by hemodialysis with citrate-enriched dialysis solution. Kidney Blood Press Res. 2015;40(1):13-21. https://doi.org/10.1159/000368478.

10. Gabutti L, Lucchini B, Marone C, Alberio L, Burnier M. Citrate- vs. acetatebased dialysate in bicarbonate haemodialysis: consequences on haemodynamics, coagulation, acid-base status, and electrolytes. BMC Nephrol. 2009;10:7.

11. Sakaguchi Y, Hamano Y, Kubota K, Oka T, Yamaguchi S, Matsumoto A, et al. Anion gap as a determinant of ionized fraction of divalent cations in hemodialysis patients. Clin J Am Soc Nephrol. 2018;13(2):274-81. https://doi. org/10.2215/CJN.07930717.

12. Maggioni A, Orzalesi M, Mimouni FB. Intravenous correction of neonatal hypomagnesemia: effect on ionized magnesium. J Pediatr. 1998;132(4):6525. https://doi.org/10.1016/50022-3476(98)70355-5.

13. Brookes $\mathrm{Cl}$, Fry $\mathrm{CH}$. lonised magnesium and calcium in plasma from healthy volunteers and patients undergoing cardiopulmonary bypass. Br Heart J. 1993;69(5):404-8. https://doi.org/10.1136/hrt.69.5.404.

14. Grooteman MPC, van den Dorpel MA, Bots ML, Penne EL, van der Weerd NC, Mazairac AHA, et al. Effect of online hemodiafiltration on all-cause mortality and cardiovascular outcomes. J Am Soc Nephrol. 2012;23(6):108796. https://doi.org/10.1681/ASN.2011121140.

15. Maduell F, Moreso F, Pons M, Ramos R, Mora-Macià J, Carreras J, et al. Highefficiency postdilution online hemodiafiltration reduces all-cause mortality in hemodialysis patients. J Am Soc Nephrol. 2013;24(3):487-97. https://doi. org/10.1681/ASN.2012080875.
16. Ok E, Asci G, Toz H, Ok ES, Kircelli F, Yilmaz M, et al. Mortality and cardiovascular events in online haemodiafiltration (OL-HDF) compared with high-flux dialysis: results from the turkish OL-HDF study. Nephrol Dial Transplant. 2013;28(1):192-202. https://doi.org/10.1093/ndt/gfs407.

17. Masai M, Sakai T, Uchino J, Ishimaru A, Inomata F, Yoshida T. Hemodialysis using Carbostar improves calcium homeostasis by correction of metabolic acidosis. J Jpn Soc Dial Ther. 2012;45(8):635-44. https://doi.org/10.4009/ jsdt.45.635.

18. Tanaka Y, Michiwaki H, Asa H, Hirose D, Tao T, Minakuchi J. Multipotentials of new asymmetric cellulose triacetate membrane for on-line hemodiafiltration both in postdilution and predilution. Ren Replace Ther. 2019;5(1):21. https://doi.org/10.1186/s41100-019-0215-x.

19. Kuroda M, Nishimura Y, Shimizu M, Enomoto M, Takata S, Ogita K, et al. Fundamental study of a bicarbonate dialysate acidified with citric acid. J Jpn Soc Dial Ther. 2010:43(11):899-908. https://doi.org/10.4009/jsdt.43.899.

20. Bosticardo G, Malberti F, Basile C, Leardini L, Libutti P, Filiberti O, et al. Optimizing the dialysate calcium concentration in bicarbonate haemodialysis. Nephrol Dial Transplant. 2012;27(6):2489-96. https://doi.org/1 0.1093/ndt/gfr733.

21. Yasue T, Ozawa S, Arai Y. Measurement of ion sequestering ability of various complexing agents for calcium and magnesium in aqueous solution. CSJ. 1986;6:767-70.

\section{Publisher's Note}

Springer Nature remains neutral with regard to jurisdictional claims in published maps and institutional affiliations.

\section{Ready to submit your research? Choose BMC and benefit from:}

- fast, convenient online submission

- thorough peer review by experienced researchers in your field

- rapid publication on acceptance

- support for research data, including large and complex data types

- gold Open Access which fosters wider collaboration and increased citations

- maximum visibility for your research: over $100 \mathrm{M}$ website views per year

At BMC, research is always in progress.

Learn more biomedcentral.com/submissions 